$12-17-2021$

\title{
The mRNA-LNP platform's lipid nanoparticle component used in preclinical vaccine studies is highly inflammatory
}

\author{
Sonia Ndeupen \\ Thomas Jefferson University \\ Zhen Qin \\ Thomas Jefferson University \\ Sonya Jacobsen \\ Thomas Jefferson University \\ Aurélie Bouteau \\ Thomas Jefferson University
} Follow this and additional works at: https://jdc.jefferson.edu/mifp

JPlaats ofetfferislordldaivernsitynology Commons, and the Medical Microbiology Commons Let us know how access to this document benefits you

See next page for additional authors

\section{Recommended Citation}

Ndeupen, Sonia; Qin, Zhen; Jacobsen, Sonya; Bouteau, Aurélie; Estanbouli, Henri; and Igyártó, Botond Z., "The mRNA-LNP platform's lipid nanoparticle component used in preclinical vaccine studies is highly inflammatory" (2021). Department of Microbiology and Immunology Faculty Papers. Paper 136.

https://jdc.jefferson.edu/mifp/136

This Article is brought to you for free and open access by the Jefferson Digital Commons. The Jefferson Digital Commons is a service of Thomas Jefferson University's Center for Teaching and Learning (CTL). The Commons is a showcase for Jefferson books and journals, peer-reviewed scholarly publications, unique historical collections from the University archives, and teaching tools. The Jefferson Digital Commons allows researchers and interested readers anywhere in the world to learn about and keep up to date with Jefferson scholarship. This article has been accepted for inclusion in Department of Microbiology and Immunology Faculty Papers by an authorized administrator of the Jefferson Digital Commons. For more information, please contact: JeffersonDigitalCommons@jefferson.edu. 


\section{Authors}

Sonia Ndeupen, Zhen Qin, Sonya Jacobsen, Aurélie Bouteau, Henri Estanbouli, and Botond Z. Igyártó 


\section{Article}

\section{The mRNA-LNP platform's lipid nanoparticle component used in preclinical vaccine studies is highly inflammatory}

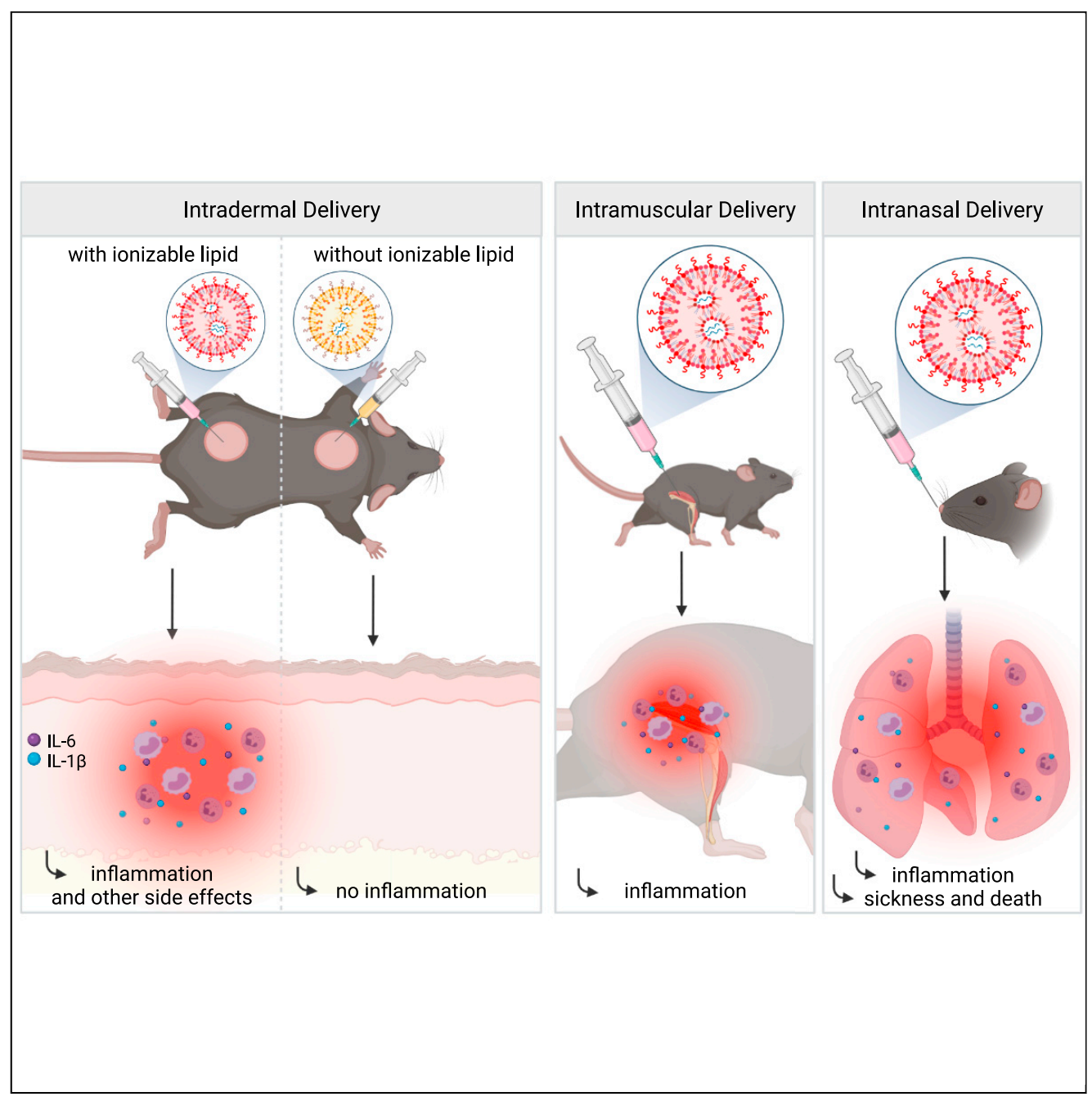

Sonia Ndeupen, Zhen Qin, Sonya Jacobsen, Aurélie Bouteau, Henri Estanbouli, Botond Z. Igyártó

botond.igyarto@jefferson.edu

Highlights

Lipid nanoparticles (LNPs) used for preclinical studies are highly inflammatory

The LNPs activate multiple inflammatory pathways and induce IL-1 $\beta$ and IL-6

The LNPs' inflammatory properties stem from their ionizable lipid component

The LNPs could be responsible for adjuvanticity and some of the side effects 


\title{
Article \\ The mRNA-LNP platform's lipid nanoparticle component used in preclinical vaccine studies is highly inflammatory
}

\author{
Sonia Ndeupen, ${ }^{1,2}$ Zhen Qin, ${ }^{1,2}$ Sonya Jacobsen, ${ }^{1}$ Aurélie Bouteau, ${ }^{1}$ Henri Estanbouli, ${ }^{1}$ and Botond Z. Igyártó ${ }^{1,3, *}$
}

\begin{abstract}
SUMMARY
Vaccines based on mRNA-containing lipid nanoparticles (LNPs) are a promising new platform used by two leading vaccines against COVID-19. Clinical trials and ongoing vaccinations present with varying degrees of protection levels and side effects. However, the drivers of the reported side effects remain poorly defined. Here we present evidence that Acuitas' LNPs used in preclinical nucleoside-modified mRNA vaccine studies are highly inflammatory in mice. Intradermal and intramuscular injection of these LNPs led to rapid and robust inflammatory responses, characterized by massive neutrophil infiltration, activation of diverse inflammatory pathways, and production of various inflammatory cytokines and chemokines. The same dose of LNP delivered intranasally led to similar inflammatory responses in the lung and resulted in a high mortality rate, with mechanism unresolved. Thus, the mRNA-LNP platforms' potency in supporting the induction of adaptive immune responses and the observed side effects may stem from the LNPs' highly inflammatory nature.
\end{abstract}

\section{INTRODUCTION}

The nucleoside-modified mRNA-LNP vaccine platform used by Pfizer/BioNTech and Moderna in their SARS-CoV-2 vaccines has been widely tested in preclinical studies, and its effectiveness in supporting Tfh cells and protective humoral immune responses matches or surpasses other vaccines (Alameh et al., 2020). These vaccines' mRNA component is nucleoside modified to decrease potential innate immune recognition (Karikó et al., 2005; Karikó et al., 2008). The LNP was chosen as a carrier vehicle to protect the mRNA from degradation and aid intracellular delivery and endosomal escape. The LNPs consist of a mixture of phospholipids, cholesterol, PEGylated lipids, and cationic or ionizable lipids. The phospholipids and cholesterol have structural and stabilizing roles, whereas the PEGylated lipids support prolonged circulation. The cationic/ionizable lipids are included to allow the complexing of the negatively charged mRNA molecules and enable the exit of the mRNA from the endosome to the cytosol for translation (Samaridou et al., 2020). The ionizable lipids were developed to decrease the highly inflammatory and cytotoxic effects of some of the permanently charged cationic lipids (Kulkarni et al., 2018). A preclinical study showed that nucleoside-modified mRNA complexed with Acuitas Therapeutics' LNPs containing proprietary ionizable lipid has adjuvant activity (Pardi et al., 2018a). However, the potential inflammatory nature of these LNPs was not assessed (Alameh et al., 2020; Pardi et al., 2018a).

The human clinical trials of the Pfizer/BioNTech and Moderna vaccines have reported side effects such as pain, swelling, fever, and sleepiness (Jackson et al., 2020; Sahin et al., 2020; Walsh et al., 2020). Under the presumption that this vaccine platform is noninflammatory, some of the clinicians and public health communicators interpreted these reported acute side effects as the vaccine being potent and generating an adaptive immune response. These side effects, however, are more in line with acute inflammatory responses induced by the vaccine. Still, no studies have been undertaken to characterize the immediate innate inflammatory reactions induced by this vaccine platform that could potentially cause the local and systemic side effects. Therefore, in this study, we took a systematic approach, focusing our attention on the injection site and analyzing the inflammatory reactions caused by the LNPs used for preclinical vaccine studies (Awasthi et al., 2019; Laczkó et al., 2020; Lederer et al., 2020; Pardi et al., 2017, 2018a, 2018b). Using complementary techniques, we show that in mice intradermal, intramuscular, or intranasal delivery of LNPs used in preclinical studies triggers inflammation characterized by leukocytic infiltration, activation of
${ }^{1}$ Department of Microbiology and Immunology, Thomas Jefferson University, Philadelphia 19107 PA, USA ${ }^{2}$ These authors contributed equally

3Lead contact

*Correspondence: botond.igyarto@jefferson. edu

https://doi.org/10.1016/j.isci. 2021.103479 
different inflammatory pathways, and secretion of a diverse pool of inflammatory cytokines and chemokines. Thus, the inflammatory milieu induced by the LNPs could be partially responsible for reported side effects of mRNA-LNP-based SARS-CoV-2 vaccines in humans and are possibly contributory to their reported high potency for eliciting antibody responses.

\section{RESULTS}

Intradermal and intramuscular inoculation with LNPs induces robust inflammation

mRNAs combined with LNPs were used in many preclinical studies and are key components of the recent Pfizer/BioNTech and Moderna SARS-CoV-2 vaccine (Alameh et al., 2020; Jackson et al., 2020; Sahin et al., 2020; Walsh et al., 2020). The mechanism of action of this mRNA-LNP platform is not well defined. The mRNA component is modified to decrease the engagement of innate immune sensors (Karikó et al., 2005; Karikó et al., 2008), but the mRNA complexed with LNPs was shown to have adjuvant activity (Pardi et al., 2018a). The mRNA-LNP platform promotes robust humoral immune responses, and humans receiving the vaccine often presented with typical acute side effects of inflammation, such as pain, swelling, and fever (Jackson et al., 2020). Based on these observations, we hypothesized that mRNA-LNP adjuvant activity and the reported side effects in humans could stem from the LNPs' inflammatory properties. mRNAs complexed with LNPs were used in preclinical studies at doses ranging from 3 to $30 \mu \mathrm{g} / \mathrm{mouse}$ (Laczkó et al., 2020; Pardi et al., 2018a). We injected $10 \mu \mathrm{g}$ (4 spots; $2.5 \mu \mathrm{g} / \mathrm{spot}$ ) of these empty LNPs formulated in phosphate buffered saline (PBS) or control PBS intradermally into adult wild-type (WT) C57BL/6 (B6) mice. We sacrificed the mice at different time points post-injection, and $\sim 1 \mathrm{~cm}^{2}$ skin samples from the injection sites were collected. The LNP-injected skin samples macroscopically showed signs of intense inflammation, such as redness and swelling (Figure 1A). Single-cell suspensions were prepared from these samples and analyzed for infiltrates using flow cytometry (Figures $1 \mathrm{~B}$ and S1A). Flow cytometry revealed massive and rapid leukocytic infiltrates dominated by neutrophils that slowly resolved by day 14 (Figure 1B). Removal of the ionizable lipid component from the LNPs abolished visible skin inflammation (Figure 1C) and the leukocytic infiltration (Figure 1D). Thus, LNPs used in preclinical studies promote swift inflammatory responses at the injection site, which depends on the ionizable lipid component.

The preclinical animal vaccine studies with this mRNA-LNP platform were carried out through intramuscular and intradermal inoculations. Both delivery routes led to robust humoral immune responses (Laczkó et al., 2020; Pardi et al., 2018a). The current mRNA-LNP-based human SARS-CoV-2 vaccines are delivered intramuscularly, which might be motivated by clinical practicality (Ols et al., 2020). To test whether intramuscular delivery also leads to inflammation, we injected animals intramuscularly with $10 \mu \mathrm{g}$ of LNPs in $30 \mu \mathrm{L}$ of PBS or PBS alone. Twenty-four hours later, the injected muscles were collected for analysis. Similar to the skin, we observed robust neutrophil infiltration to the muscle samples that received LNPs (Figures 1E and S1B). The muscles injected with LNPs also showed a significant increase in weight (Figure 1F). Thus, these findings collectively indicate massive local inflammation that could account for some of the reported local side effects.

To acquire a more in-depth understanding of the global changes triggered by the injection of the LNPs, we repeated the intradermal experiments presented above with LNPs complexed with control, noncoding polycytosine mRNA. Skin samples harvested one day after injection were split into two and analyzed using Luminex and bulk RNA-seq (Figure 2A). The Luminex data corroborated the flow cytometry findings and demonstrated the presence of a variety of inflammatory cytokines and chemokines (Figures 2B, 2C and S2), in comparison to control samples. Chemokines that attract neutrophils and monocytes and promote their functions, such as CCL2, CCL3, CCL4, CCL7, CCL12, CXCL1, and CXCL2, dominated the panel (Figure 2B). We further found large amounts of interleukin-1 $\beta$ (IL-1 $\beta$ ), granulocyte-macrophage colony-stimulating factor (GM-CSF), and IL-6, the signature cytokines of inflammatory responses (Figure 2C). Our RNA-seq analysis revealed that thousands of genes were upregulated (Figure 2D) upon LNP injection. With $p<0.05$ and FDR $<0.05,9,508$ genes and 8,883 genes, respectively, were differentially expressed. More importantly, confirming our flow cytometry and Luminex data, the genes associated with monocyte/granulocyte development, recruitment, and function (Cxcl1, Cxcl2, $\mathrm{Cxcl} 5, \mathrm{Cxcl} 10, \mathrm{Ccl} 2, \mathrm{Ccl} 3, \mathrm{Ccl} 4, \mathrm{Ccl} 7, \mathrm{Ccl} 12, \mathrm{Csf2}$, and $\mathrm{Csf3}$ ) and inflammation (I/1b and I/6) showed the highest fold increases over the control samples (Figure 2E). We also observed significant upregulation of gene transcripts associated with activation of inflammasomes, such as $1 / 1 \mathrm{~b}$ and N/rp3, and downregulation of N/rp10, which is known to inhibit inflammasomes (Figure 2E). Gene set enrichment analyses (GSEA) showed the activation of many different inflammatory pathways, including, but not limited to, viral infections, RIG-I, NOD-like, and Tolllike receptor signaling (Figure 2F). Pro-apoptotic and necroptotic gene sets were also significantly upregulated, as well as interferon signaling (Figure 2F). 


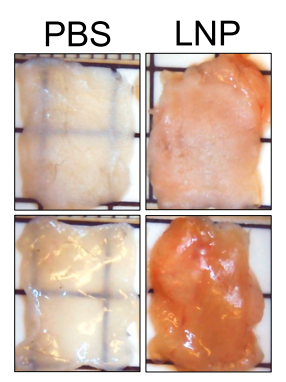

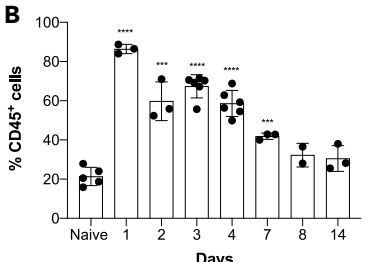

Days

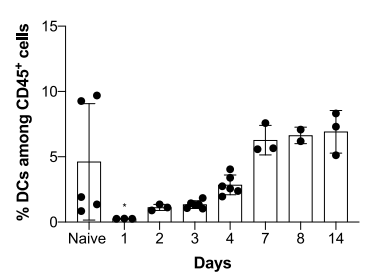

C

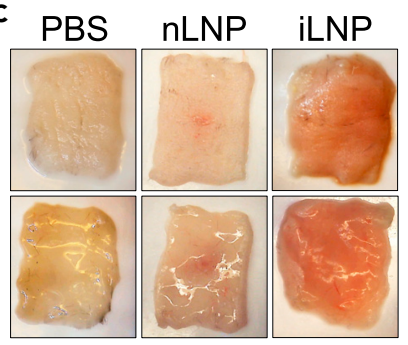

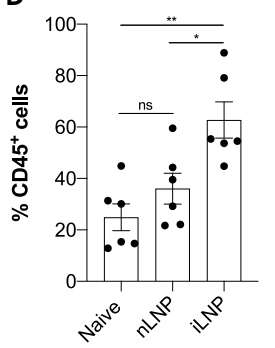
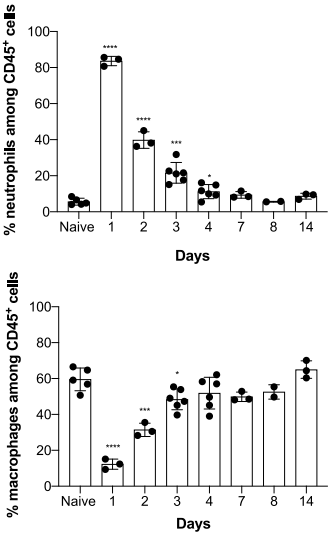
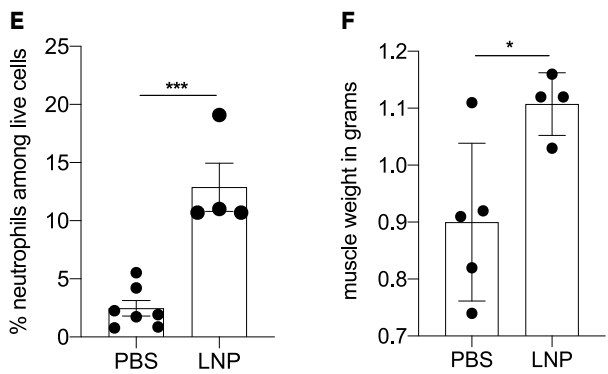

Figure 1. Intradermal inoculation with LNPs induces robust inflammation

(A) Intradermal inoculation with LNP induced visible levels of inflammation. Pictures were taken $24 \mathrm{~h}$ after PBS or LNP injection.

(B) Skin samples from the mice injected with PBS or LNPs $(2.5 \mu \mathrm{g} / \mathrm{spot})$ were harvested at the indicated time points, analyzed by flow cytometry, and displayed as cell percentages.

(C) As in A, but LNPs with (iLNP) or without (nLNP) ionizable lipids were used. Unlike iLNPs the nLNPs induced no visible signs of inflammation.

(D) Skin samples from C were analyzed for leukocytic infiltration $24 \mathrm{~h}$ post-inoculation.

(E) Muscle samples from the mice injected with PBS or $10 \mu \mathrm{g}$ LNPs were analyzed for neutrophil infiltration $24 \mathrm{~h}$ postinoculation.

(F) The weight of muscle samples from $E$ are shown. For all the charts the data were pooled from two separate experiments and displayed as percent \pm SD. Each dot represents a separate animal. Student's two-tailed t test was used to determine the significance between naive and the experimental samples. ${ }^{\star * \star *} p<0.0001,{ }^{\star * *} p<0.0005,{ }^{\star \star} p<0.005$, ${ }^{*} \mathrm{p}<0.05$, ns = not significant. No significant differences were observed between samples harvested from naive or PBStreated animals and are used interchangeably throughout the manuscript.

See also Figure S1. 
A

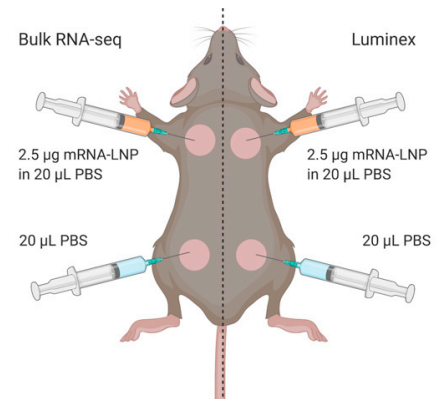

C

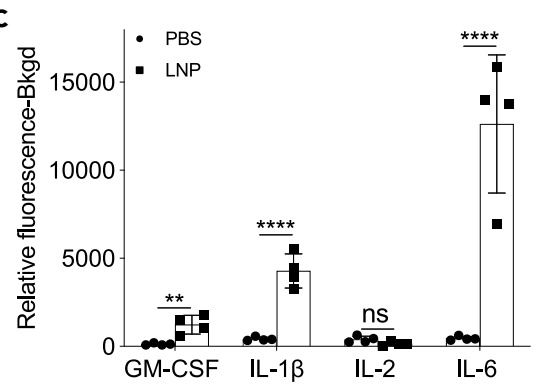

E

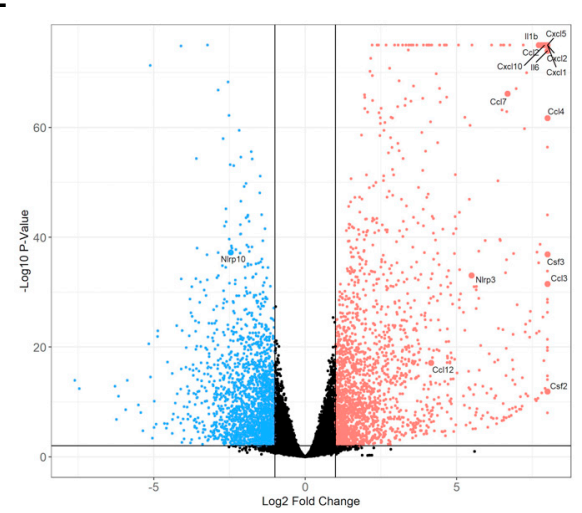

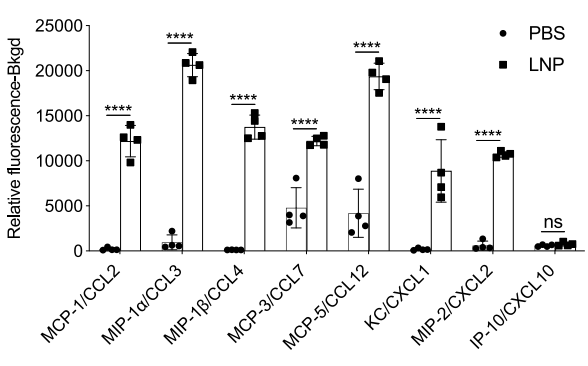

D

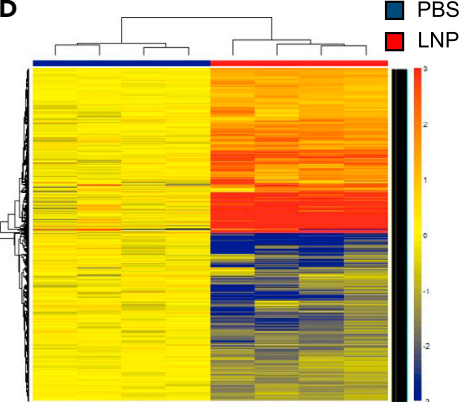

$\mathbf{F}$

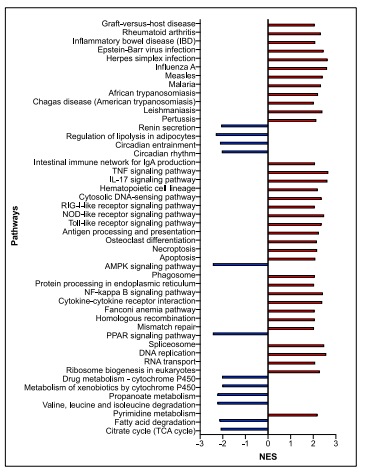

Figure 2. Intradermal inoculation with LNPs complexed with noncoding poly-cytosine mRNA leads to an inflammatory milieu

(A) Experimental design. The mice were treated as indicated, and $24 \mathrm{~h}$ later, the skin samples were prepared for Luminex and bulk RNA-seq analyses.

( $B$ and $C$ ) Luminex data summarizing inflammatory chemokines and cytokines induced by the LNPs.

See also Figure S2.

(D) Heatmap of gene expression changes triggered by the LNPs (FDR $<0.05, \log 2$ FC $>1-4091$ genes).

(E) Volcano plot summarizing the up- and downregulated genes upon LNP injection.

(F) GSEA analyses of the KEGG pathways and displayed as normalized enrichment score (NES). FDR $<0.05$. Pathways with NES less than \pm 2 are not displayed. $N=4$.

In summary, using different techniques, we show that LNPs, alone or complexed with control noncoding poly-cytosine mRNA, are highly inflammatory in mice, likely through the engagement and activation of various distinct and convergent inflammatory pathways.

Intranasal inoculation with LNPs leads to robust inflammatory responses in the lung Respiratory infections, including with SARS-CoV-2, induce a dominant mucosa-protective antibody response and local T-cell-mediated immunity (Grau-Expósito et al., 2021; Russell et al., 2020; Sterlin et al., 2021). Therefore, to achieve an immune response that mimic natural infection and might confer more protection against SARS-CoV-2 at the levels of the respiratory tract (Lund and Randall, 2021; 
PBS

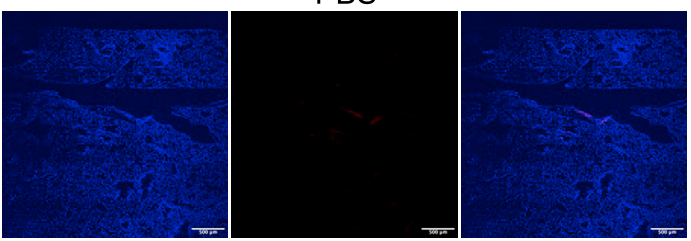

Dil-LNP

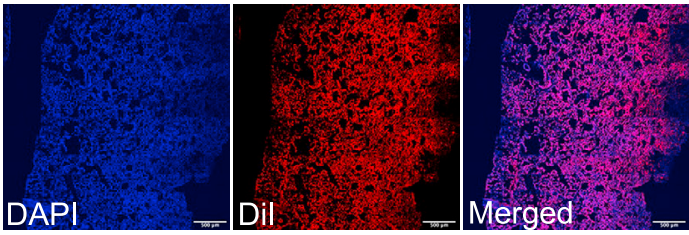

B

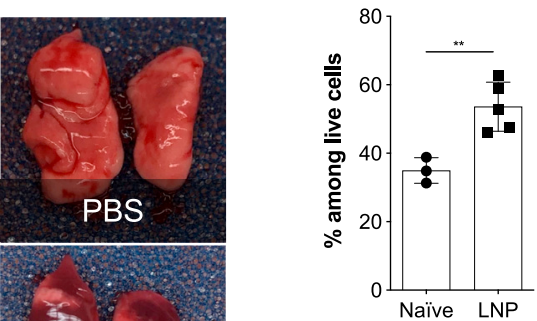

C

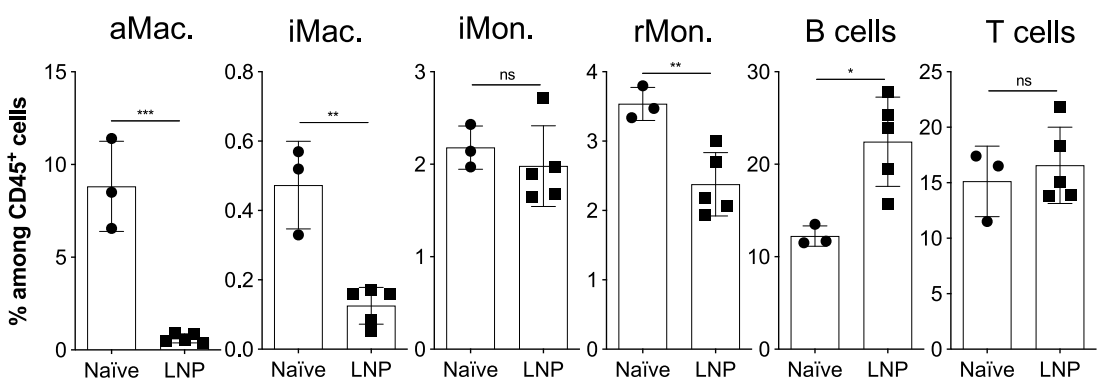

D

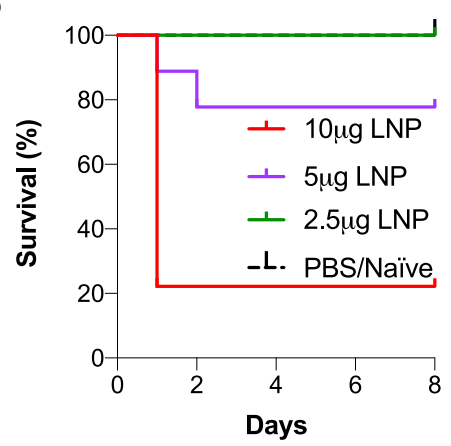

E

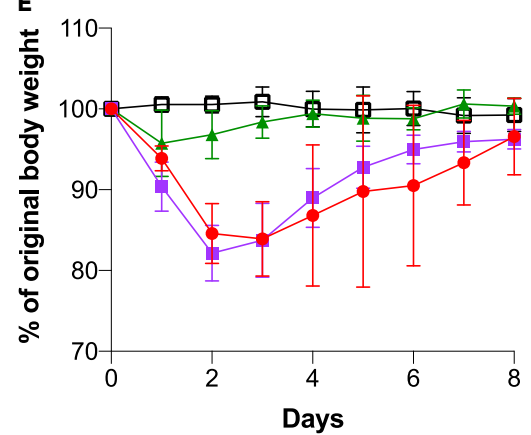

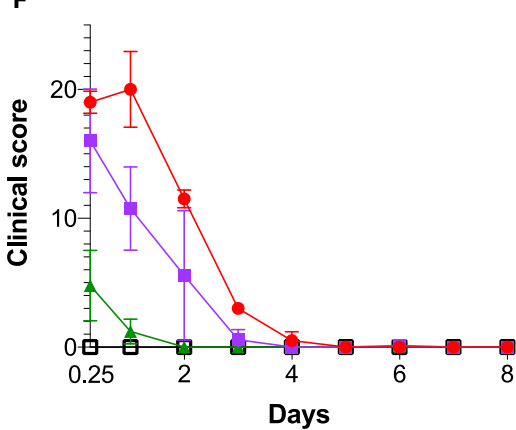

Figure 3. Intranasal LNP delivery induces robust lung inflammation

(A) LNP injection leads to fast and homogeneous dispersion in the lung. Animals were inoculated with PBS or $10 \mu \mathrm{g}$ of Dil-labeled LNP. Six hours later the lungs were harvested, prepared for histology, stained with DAPI, and imaged using a confocal microscope. One representative image is shown. 
Figure 3. Continued

(B) Lungs harvested at the indicated time points from PBS, and the $10 \mu \mathrm{g}$ LNP group were harvested and photographed.

(C) Animals inoculated with $10 \mu \mathrm{g}$ of LNP were sacrificed $9 \mathrm{~h}$ post inoculation and their lungs' leukocytic composition determined by flow cytometry following a published gating strategy (Yu et al., 2016). Neut. = neutrophils, Eosi. = eosinophils, DC = dendritic cells, NK = natural killer, aMac. = alveolar macrophages, iMac. $=$ interstitial macrophages, iMon. $=$ inflammatory monocytes, $\mathrm{rMon} .=$ resident monocytes .

(D-F) Animals were inoculated with the indicated doses of LNP and the survival rate (D), weight (E), and clinical scores (F) recorded daily for up to 8 days. Data were pooled from two independent experiments. $N=9$ for each group except PBS/naive where $n=5$. For all the charts the data were pooled from at least two separate experiments and displayed as percent \pm SD. Each dot represents a separate animal. Student's two-tailed t test was used to determine the significance between naive and the experimental samples. ${ }^{* \star} p<0.0005,{ }^{* *} p<0.005,{ }^{*} p<0.05, n s=$ not significant.

See also Figure S3.

Russell et al., 2020; Zens et al., 2019), researchers are actively working on developing SARS-CoV-2 vaccines that could be administered intranasally (Buschmann et al., 2021; Chavda et al., 2021; van Doremalen et al., 2021). Therefore, we first tested whether the LNPs can reach the lungs upon intranasal delivery. For this purpose, we inoculated mice intranasally with PBS or $10 \mu \mathrm{g}$ of Dil-labeled LNPs. Six hours later histology showed a homogeneous distribution of the LNPs in the lung tissue (Figure 3A). Next, we tested whether intranasal delivery leads to inflammation in the lungs. For this, we intranasally inoculated adult WT B6 mice with PBS or $10 \mu \mathrm{g}$ of LNPs in PBS/mouse. Lung samples from PBS- and $10 \mu \mathrm{g}$ LNP-treated mice were prepared for macroscopic analyses 9 and $24 \mathrm{~h}$ post-inoculation and for flow cytometry $9 \mathrm{~h}$ post-inoculation. In a matter of hours, the lungs turned red in color in the LNP-inoculated group (Figure 3B). As was observed for the skin and muscle, flow cytometric analyses revealed significant leukocytic infiltration dominated by neutrophils and eosinophils and a decrease in macrophages and certain dendritic cell (DC) subsets (Figures 3C and S3). Thus, intranasal delivery of LNPs leads to massive inflammation in the lungs.

With the experiments presented earlier, we observed a high mortality rate among the mice inoculated with LNPs. These findings prompted us to perform a dose-response experiment to determine the amounts of LNPs that might be safe to use for mucosal vaccination. We intranasally inoculated adult WT B6 mice with LNPs ranging from $2.5 \mu \mathrm{g}$ to $10 \mu \mathrm{g} /$ mouse and monitored their health and weight for up to 8 days. We found that $\sim 80 \%$ of mice treated with $10 \mu \mathrm{g}$ of LNP died in less than $24 \mathrm{~h}$ (Figure 3D). The $5 \mu \mathrm{g}$ dose killed $\sim 20 \%$ of the mice by that time, whereas all the $2.5 \mu \mathrm{g}$-treated mice survived and showed no weight drop (Figure 3D) and no significant clinical signs of distress (Figure 3E). For the 5 and $10 \mu \mathrm{g}$ doses, the surviving mice showed notable clinical scores of distress, such as shaking/shivering, and they lost weight significantly during the first 2 days of treatment (Figures $3 E$ and $3 F$ ). After the first $\sim 3$ days, these mice did not continue to show significant clinical scores anymore, and their weight slowly started to normalize (Figure 3E). These data suggest that careful optimization of the LNP dose might allow the use of the mRNA-LNP platform for intranasal vaccination.

\section{DISCUSSION}

Here we show that the LNPs used for many preclinical studies (Freyn et al., 2020; Laczkó et al., 2020; Lederer et al., 2020; Pardi et al., 2017, 2018a, 2018b) are highly inflammatory. This could explain their potent adjuvant activity and their superiority, compared with other adjuvants, in supporting the induction of adaptive immune responses.

Previous preclinical mouse data suggested that mRNA complexed with LNPs have adjuvant activity (Pardi et al., 2018a). The mRNA is nucleoside modified and purified to decrease activation of certain innate inflammatory pathways (Karikó et al., 2005; Karikó et al., 2008, 2011). Our injection-site-focused analyses revealed the inflammatory nature of these LNPs, which likely provides a basis for their adjuvant properties. The cationic lipid component of the lipid carriers is often inflammatory and cytotoxic (Filion and Phillips, 1997, 1998; Lv et al., 2006; Samaridou et al., 2020; Sedic et al., 2018; Tao et al., 2011). The ionizable lipids were developed to overcome the inflammatory nature of the permanently charged cationic lipids (Kulkarni et al., 2018). However, we found that the proprietary ionizable lipid component of these LNPs is inflammatory (Figures 1C and 1D). The inflammatory responses triggered by the LNPs alone or complexed with mRNAs were independent of the delivery route and were dominated by neutrophil infiltration. Despite the induction of phenotypically similar innate inflammatory responses, unlike intradermal and intramuscular inoculations, intranasal delivery of $2.5 \mu \mathrm{g}$ of mRNA-LNP coding for PR8 HA did not lead to detectable levels of adaptive immune responses (unpublished observation). Thus, slight differences are likely to exist between the route of administration, which warrants further investigation to optimize this platform for intranasal use. Understanding the cellular and molecular differences between intradermal/intramuscular and 
intranasal delivery sites that underline this dissimilarity in adaptive immune responses might also help to decipher why certain people do not react to the intramuscularly delivered mRNA-LNP vaccines.

Humans present various side effects, most often pain, swelling, fever, and chills, after intramuscular vaccination with the Pfizer/BioNTech or Moderna vaccines (Jackson et al., 2020; Sahin et al., 2020; Walsh et al., 2020). These are typical symptoms associated with inflammation triggered by cytokines such as IL-1 $\beta$ and IL-6 (Dinarello, 2018; Tanaka et al., 2014). Along with causing local inflammatory responses, these cytokines also act as major endogenous pyrogens (Conti, 2004) and instruct the hypothalamus to increase the body's temperature (fever) to help overcome possible infections. In concordance with this, the intradermal inoculation of LNPs in mice led to the secretion of large amounts of major and minor pyrogens, IL-1 $\beta / \mathrm{IL}-6$ and macrophage inflammatory protein- $\alpha(C C L 3)$ and macrophage inflammatory protein- $\beta(C C L 4)$, respectively (Figures $2 \mathrm{~B}$ and $2 \mathrm{C}$ ). Furthermore, the observed activation of other inflammatory pathways and cell death could further accentuate the experienced side effects. However, further studies will be needed to determine the exact nature of the inflammatory responses triggered by mRNA-LNP vaccines in humans and how much overlap there might be with the inflammatory signatures documented here for mice.

It remains to be determined how these LNPs or their ionizable lipid component activate distinct inflammatory pathways. In theory, LNPs could activate multiple pathways or alternatively engage only one that would initiate an inflammatory cascade. Some cationic/ionizable lipids bind and activate TLRs (Lonez et al., 2012, 2014; Samaridou et al., 2020; Tanaka et al., 2008). Our GSEA analyses are consistent with TLR engagement by these proprietary LNPs, among others (Figure 2F). We also observed upregulation of inflammasome components such Nlrp3 and enrichment of genes involved in necroptosis. Inflammatory cell death, such as necroptosis and pyroptosis, could cause the release of DAMPs and the further enhancement of inflammation. The synthetic ionizable lipid in the Pfizer SARS-CoV-2 vaccine has been speculated to have approximately 20-30 days of halflife in humans (Comirnaty, 2021). Whether the long-term presence of ionizable lipid could lead to low levels of chronic inflammation and immune exhaustion (Wherry and Kurachi, 2015) remain to be determined.

Intranasal inoculation with higher doses of LNPs led to a significant mortality rate. Hypothetically, the massive innate inflammatory responses induced in the lung (Figure 3) and chemical disruption of the pulmonary surfactant by cationic lipids (Boncuk et al., 1997), i.e., reduced gas exchange, cytotoxicity to alveolar cells, or other mechanisms, could all have contributed to animal death (Dokka et al., 2000). Thus, further experimentation is needed to investigate the mechanism of the toxicity. Materials of different nature including nanoparticles inoculated intranasally readily enter the central nervous system (CNS), and it is the preferred method to overcome the blood-brain barrier and deliver active substances to the brain (Costa et al., 2021; Elder et al., 2006; Gao et al., 2006; Hanson et al., 2013; Lockman et al., 2004). LNPs as lipid particles can quickly diffuse (Figure 3A) (Pardi et al., 2015) and, through intranasal delivery, could potentially gain access to the CNS at high enough levels to induce significant inflammation. Whether these LNPs reach the CNS and induce levels of inflammation that could have contributed to the animal death observed at higher doses remains to be determined. Interestingly, it has been reported that the mRNA from Moderna's mRNA-LNP vaccine injected intramuscularly could be detected in very low levels in the brain, potentially indicating that the mRNA-LNP platform might cross the blood-brain barrier and reach the CNS (Moderna, 2021). However, in this case, the scant amounts detected in the CNS would likely not induce significant inflammation but might trigger hypothalamus-driven side effects such as fever, nausea, and sleepiness. Further studies will be needed to determine whether these minimal amounts of vaccine components detected in the CNS are physiologically relevant and define whether they could exacerbate preexisting inflammatory responses reported in a small case report with MS autoimmune patients (Khayat-Khoei et al., 2021). It is important to note that a medium-sized observational study did not find an increased risk of relapse activity after mRNA-LNP vaccination in MS patients (Achiron et al., 2021), whereas others have noted a slight but increased risk of hemorrhagic stroke. However, the risk of these complications was greater following a positive SARS-CoV-2 test (Patone et al., 2021).

People often present with more severe and systemic side effects after the booster shot. This raises the possibility that the adaptive immune response might somehow amplify side effects induced by the vaccine. One culprit identified so far is PEG, which is immunogenic. Antibodies formed against PEG have been reported to support a so-called anaphylactoid, complement activation-related pseudoallergy (CARPA) reaction (Kozma et al., 2020; Szebeni, 2005, 2014). Of note, because PEG is a compound frequently used in cosmetics and toothpaste, many individuals could have anti-PEG antibodies. We have discussed other 
possible mechanisms in our recent opinion article (lgyarto et al., 2021). Briefly, although mRNA mainly transfects cells near the injection site, it could hypothetically reach any cell in the body (Maugeri et al., 2019; Pardi et al., 2015). The resulting translated protein could be presented on MHC-I in the form of peptides or displayed as a whole protein in the cell membrane. In both cases, cells with the vaccine peptide/ protein on their surfaces could be targeted and killed by cells of the adaptive and innate immune system, $\mathrm{CD}^{+} \mathrm{T}$ and natural killer (NK) cells (via antibody-dependent cellular toxicity [ADCC]), respectively. In line with this, the so-called "Covid-arm," a delayed-type hypersensitivity reaction that develops in some patients several days after vaccination (Blumenthal et al., 2021), or the myocarditis/pericarditis recently reported with some of the vaccinated people (Abu Mouch et al., 2021; Diaz et al., 2021; Marshall et al., 2021; Montgomery et al., 2021; Shay et al., 2021), or the CNS inflammation observed in a small number of vaccinated MS patients (Khayat-Khoei et al., 2021) could be indeed an indication of immune responses targeting the cells expressing the vaccine-derived peptides/proteins.

In summary, the first vaccination's side effects, except for CARPA, are likely associated with robust innate inflammation induced by the LNPs. In contrast, after the second vaccination, side effects could be further exacerbated by immune responses targeting cells expressing the vaccine protein or its peptide derivatives. Whether innate memory responses (Netea et al., 2011) to LNPs also contribute to amplifying the side effects remains to be determined (Figure 4). Overall, the robust inflammatory milieu induced by LNPs, combined with presentation of the vaccine-derived peptides/protein outside of antigen-presenting cells, might cause tissue damage and exacerbate side effects. Because self-antigen presentation in an inflammatory environment has been linked to autoimmune disease development (Janeway et al., 2001), this merits further investigation.

mRNA-LNPs support very robust adaptive immune responses in animal models and humans (Alameh et al., 2020; Jackson et al., 2020; Sahin et al., 2020). The mechanism of induction of these immune responses so far has not been fully elucidated (Ndeupen et al., 2021). Our findings revealed that LNPs used in some preclinical studies are highly inflammatory, which could explain their superiority to Food and Drug Administration (FDA)-approved adjuvants in supporting the development of Th cells and humoral immune responses. Of note, their higher efficacy probably relies on activation of different inflammatory pathways exacerbated by direct cellular toxicity. In accordance with the highly inflammatory nature of the mRNA-LNPs, we recently found that certain innate immune cells and cytokines, such as some DC subsets, neutrophils, and IL-6, show redundancy in supporting adaptive immune responses by this platform (Ndeupen et al., 2021). The inflammatory properties of these LNPs' should certainly be further exploited as an adjuvant platform in combination with proteins, subunit vaccines, or even in combination with existing attenuated vaccines (Bernasconi et al., 2021; Debin et al., 2002; Martins et al., 2007; Shirai et al., 2020; Swaminathan et al., 2016). LNPs, unlike other adjuvants, could thus serve a dual purpose as both delivery vehicles for different cargos and as an adjuvant. However, it will be necessary to strike a balance between positive adjuvant and negative inflammatory properties as LNP-associated vaccines move forward. Because vaccine doses and volumes utilized in rodents are much higher than those used in humans (Nair and Jacob, 2016), detailed dose/volume response studies will be required. Because some of the DCs can support humoral immune responses in the absence of adjuvant, noninflammatory LNPs could also be developed (Bouteau et al., 2019; Kato et al., 2020; Li et al., 2015; Yao et al., 2015).

\section{Limitations of the study}

Further studies will be needed to determine the exact nature of the inflammatory responses triggered by mRNA-LNP vaccines in humans and how much overlap there might be with the inflammatory signatures documented here for mice. Because vaccine doses and volumes utilized in rodents are much higher than those in humans, detailed dose/volume response studies will be required. Optimization of the delivery volume will be likely essential with the vaccines designed for intranasal human inoculation. Here we used a delivery volume that likely suffused the mouse lungs, whereas the amount used for humans is anticipated to limit the exposure to the nasopharynx.

\section{STAR $\star$ METHODS}

Detailed methods are provided in the online version of this paper and include the following:

- KEY RESOURCES TABLE

- RESOURCE AVAILABILITY 


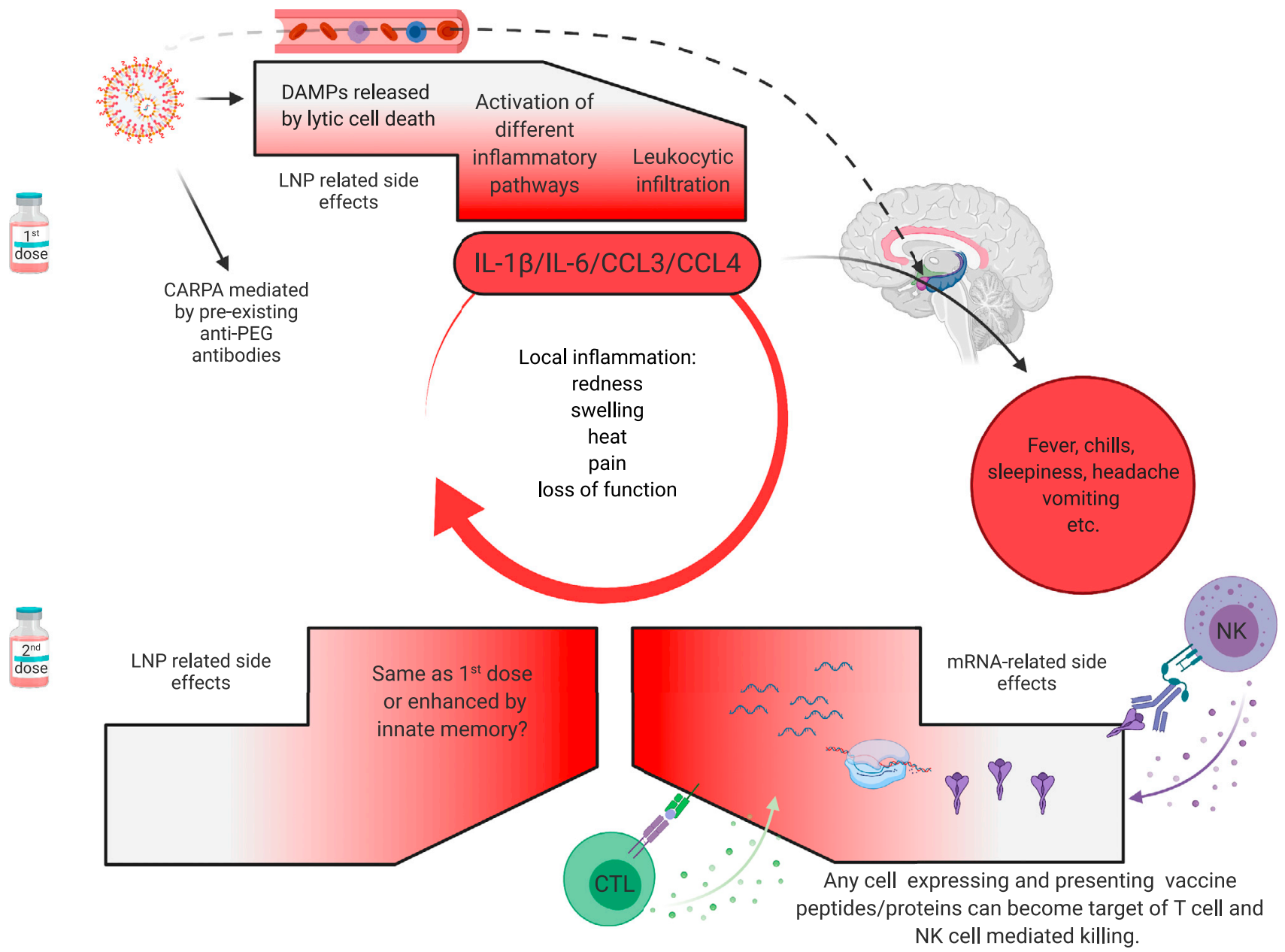

Figure 4. Potential mechanism of side effects

The side effects observed with the SARS-CoV-2 vaccine's first dose are likely associated with the LNPs' inflammatory properties. LNPs activate different inflammatory pathways that will lead to the production of inflammatory cytokines, such as IL-1 $\beta$ and IL-6, that can initiate and sustain local and systemic inflammations and side effects. The dashed line indicates the possibility that the LNPs might also diffuse from the periphery and reach any organs in the body, including CNS (hypothalamus) where they could directly induce side effects. PEG is widely used as a food and medicine additive, and many of us develop antibodies to PEG. Therefore, the LNPs' PEGylated lipids can induce CARPA in humans with preexisting PEG-specific antibodies. Humans often experience more severe side effects with the second dose. Here we posit that might be due to multiple reasons. Firstly, innate immune memory against the LNPs might form after the first vaccination and that could lead to even more robust inflammatory responses upon the second vaccination. Secondly, after the first vaccination, adaptive immune responses are formed targeting the viral protein coded by the mRNA. As such, cells (shown as red shape) expressing the viral protein-derived peptides or protein itself can become the target of CD8 ${ }^{+} \mathrm{T}$ - or NK-cell-mediated killing (ADCC), respectively. Because the LNPs could diffuse throughout the body and transfect any cell in their path with the mRNA, and the mRNA could also be further distributed through extracellular vesicles (Maugeri et al., 2019), the target population could potentially be vast and diverse.

○ Lead contact

O Materials availability

Data and code availability

- EXPERIMENTAL MODEL AND SUBJECT DETAILS

O Mice

- METHOD DETAILS

O Reagents

Intradermal inoculation and flow cytometry analyses

Intramuscular inoculation and flow cytometry analyses

○ Luminex ${ }^{\circledR}$

RNA preparation, sequencing, data analyses and visualization 
O Intranasal inoculation and flow cytometry analyses

- QUANTIFICATION AND STATISTICAL ANALYSIS

\section{SUPPLEMENTAL INFORMATION}

Supplemental information can be found online at https://doi.org/10.1016/j.isci.2021.103479.

\section{ACKNOWLEDGMENTS}

This work was supported by departmental start-up funds and by R01Al146420 to B.Z.I. We thank the following core facilities for their help and assistance: genomic, proteomics, flow cytometry, and the imaging core. Special thank you for the constructive comments received online. Figures were generated using BioRender.

\section{AUTHOR CONTRIBUTIONS}

B.Z.I. conceptualized the study, interpreted the data, and wrote the manuscript. S.N. and A.B. performed the intradermal/intramuscular mouse experiments and analyzed data. S.J. prepared figures. Z.Q. did the intranasal/intramuscular experiments and analyzed the resulting data. H.E. assisted with the microscopy.

\section{DECLARATION OF INTERESTS}

Authors declare no conflict of any sort.

Received: May 10, 2021

Revised: September 3, 2021

Accepted: November 17, 2021

Published: December 17, 2021

\section{REFERENCES}

Abu Mouch, S., Roguin, A., Hellou, E., Ishai, A., Shoshan, U., Mahamid, L., Zoabi, M., Aisman, M., Goldschmid, N., and Berar Yanay, N. (2021).

Myocarditis following COVID-19 mRNA vaccination. Vaccine $39,3790-3793$

Achiron, A., Dolev, M., Menascu, S., Zohar, D.-N., Dreyer-Alster, S., Miron, S., Shirbint, E. Magalashvili, D., Flechter, S., Givon, U., et al. (2021). COVID-19 vaccination in patients with multiple sclerosis: what we have learnt by February 2021. Mult. Scler. J. 27, 864-870

Alameh, M.-G., Weissman, D., and Pardi, N (2020). Messenger RNA-based vaccines against infectious diseases. Curr. Top. Microbiol. Immunol. 1-35. https://doi.org/10.1007/ 82_2020_202.

Awasthi, S., Hook, L.M., Pardi, N., Wang, F., Myles, A., Cancro, M.P., Cohen, G.H., Weissman, D., and Friedman, H.M. (2019). Nucleosidemodified mRNA encoding HSV-2 glycoproteins C, D, and E prevents clinical and subclinica genital herpes. Sci. Immunol. 4, eaaw7083.

Bernasconi, V., Norling, K., Gribonika, I., Ong, L.C., Burazerovic, S., Parveen, N., Schön, K., Stensson, A., Bally, M., Larson, G., et al. (2021). A vaccine combination of lipid nanoparticles and a cholera toxin adjuvant derivative greatly improves lung protection against influenza virus infection. Mucosal Immunol. 14, 523-536.

Blumenthal, K.G., Freeman, E.E., Saff, R.R., Robinson, L.B., Wolfson, A.R., Foreman, R.K., Hashimoto, D., Banerji, A., Li, L., Anvari, S., et al. (2021). Delayed large local reactions to mRNA1273 vaccine against SARS-CoV-2. N. Engl. J. Med. 384, 1273-1277.
Boncuk, P., Kaser, M., Yu, Y., and Taeusch, H.W. (1997). Effects of cationic liposome-DNA complexes on pulmonary surfactant function in vitro and in vivo. Lipids 32, 247-253.

Bouteau, A., Kervevan, J., Su, Q., Zurawski, S.M. Contreras, V., Dereuddre-Bosquet, N., Le Grand R., Zurawski, G., Cardinaud, S., Levy, Y., et al. (2019). DC subsets regulate humoral immune responses by supporting the differentiation of distinct Tfh cells. Front. Immunol. 10, 1134

Buschmann, M.D., Carrasco, M.J., Alishetty, S., Paige, M., Alameh, M.G., and Weissman, D. (2021). Nanomaterial delivery systems for mrna vaccines. Vaccines $9,1-30$.

Chavda, V.P., Vora, L.K., Pandya, A.K., and Patravale, V.B. (2021). Intranasal vaccines for SARS-CoV-2: from challenges to potential in COVID-19 management. Drug Discov. Today 26, 2619-2636.

Comirnaty. (2021). Assessment Report COVID-19 Vaccine Comirnaty. EMA/707383/2020 Corr.1* 31, pp. 1-140. https://www.ema.europa.eu/en/ documents/assessment-report/comirnaty-eparpublic-assessment-report_en.pdf.

Conti, B. (2004). Cytokines and fever. Front. Biosci. 9, 1433.

Costa, C.P., Moreira, J.N., Sousa Lobo, J.M., and Silva, A.C. (2021). Intranasal delivery of nanostructured lipid carriers, solid lipid nanoparticles and nanoemulsions: a current overview of in vivo studies. Acta Pharm. Sin. B 11 925-940.
Debin, A., Kravtzoff, R., Santiago, J.V., Cazales, L., Sperandio, S., Melber, K., Janowicz, Z., Betbeder, D., and Moynier, M. (2002). Intranasal immunization with recombinant antigens associated with new cationic particles induces strong mucosal as well as systemic antibody and CTL responses. Vaccine 20, 2752-2763.

Diaz, G.A., Parsons, G.T., Gering, S.K., Meier, A.R., Hutchinson, I.V., and Robicsek, A. (2021). Myocarditis and pericarditis after vaccination for COVID-19. JAMA 326, 1210-1212.

Dinarello, C.A. (2018). Overview of the IL-1 family in innate inflammation and acquired immunity. Immunol. Rev. 281, 8-27.

Dokka, S., Toledo, D., Shi, X., Castranova, V., and Rojanasakul, Y. (2000). Oxygen Radical-Mediated Pulmonary lack of immunogenicity, simplicity and ease of production make. Pharm. Res. 17, 521-525.

van Doremalen, N., Purushotham, J.N., Schulz, J.E., Holbrook, M.G., Bushmaker, T., Carmody, A., Port, J.R., Yinda, C.K., Okumura, A., Saturday, G., et al. (2021). Intranasal ChAdOx1 nCoV-19/ AZD1222 vaccination reduces viral shedding after SARS-CoV-2 D614G challenge in preclinical models. Sci. Transl. Med. 13, eabh0755.

Elder, A., Gelein, R., Silva, V., Feikert, T., Opanashuk, L., Carter, J., Potter, R., Maynard, A., Ito, Y., Finkelstein, J., et al. (2006). Translocation of inhaled ultrafine manganese oxide particles to the central nervous system. Environ. Health Perspect. 114, 1172-1178.

Filion, M.C., and Phillips, N.C. (1997). Toxicity and immunomodulatory activity of liposomal vectors 
formulated with cationic lipids toward immune effector cells. Biochim. Biophys. Acta. Biomembr. $1329,345-356$.

Filion, M.C., and Phillips, N.C. (1998). Major Limitations in the Use of Cationic Liposomes for DNA Delivery. Int. J. Pharm. 162, 159-170.

Freyn, A.W., Ramos da Silva, J., Rosado, V.C. Bliss, C.M., Pine, M., Mui, B.L., Tam, Y.K., Madden, T.D., de Souza Ferreira, L.C., Weissman, D., et al. (2020). A multi-targeting, nucleosidemodified mRNA influenza virus vaccine provides broad protection in mice. Mol. Ther. 28, 15691584

Gao, X., Tao, W., Lu, W., Zhang, Q., Zhang, Y., Jiang, $X$, and $F u$, S. (2006). Lectin-conjugated PEG-PLA nanoparticles: preparation and brain delivery after intranasal administration. Biomaterials 27, 3482-3490.

Grau-Expósito, J., Sánchez-Gaona, N., Massana, N., Suppi, M., Astorga-Gamaza, A., Perea, D. Rosado, J. Falcó, A Kirkegaard C. Torrella, A. et al. (2021). Peripheral and lung resident memory T cell responses against SARS-CoV-2. Nat. Commun. 12,3010.

Hanson, L.R., Fine, J.M., Svitak, A.L., and Faltesek, K.A. (2013). Intranasal administration of CNS Therapeutics to awake mice. J. Vis. Exp. e4440. https://doi.org/10.3791/4440.

Igyártó, B.Z Jacobsen, S, and Ndeupen, S (2021). Future considerations for the mRNA-lipid nanoparticle vaccine platform. Curr. Opin. Virol. $48,65-72$

Jackson, L.A., Anderson, E.J., Rouphael, N.G., Roberts, P.C., Makhene, M., Coler, R.N., McCullough, M.P., Chappell, J.D., Denison, M.R., Stevens, L.J., et al. (2020). An mRNA vaccine against SARS-CoV-2 - preliminary report. N. Engl. J. Med. 383, 1920-1931.

Janeway, C.A., Travers, P., Walport, M., and Shlomchik, M.J. (2001). Self-tolerance and its loss. In Immunobiology: The Immune System in Health and Disease, Fifth Edition, pp. 636-654

Kanehisa, M. (2000). KEGG: kyoto encyclopedia of genes and genomes. Nucleic Acids Res. 28, $27-30$.

Karikó, K., Buckstein, M., Ni, H., and Weissman, D. (2005). Suppression of RNA recognition by tolllike receptors: the impact of nucleoside modification and the evolutionary origin of RNA. Immunity 23, 165-175.

Karikó, K., Muramatsu, H., Ludwig, J., and Weissman, D. (2011). Generating the optimal mRNA for therapy: HPLC purification eliminates immune activation and improves translation of nucleoside-modified, protein-encoding mRNA Nucleic Acids Res. 39, e142

Karikó, K., Muramatsu, H., Welsh, F.A., Ludwig, J. Kato, H., Akira, S., and Weissman, D. (2008). Incorporation of pseudouridine into mRNA yields superior nonimmunogenic vector with increased translational capacity and biological stability. Mol. Ther. 16, 1833-1840.

Kashem, S.W., and Kaplan, D.H. (2018). Isolation of murine skin resident and migratory dendritic cells via enzymatic digestion. Curr. Protoc. Immunol. 121, e45.
Kato, Y., Steiner, T.M., Park, H.-Y., Hitchcock, R.O.,Zaid, A., Hor, J.L., Devi, S., Davey, G.M. Vremec, D., Tullett, K.M., et al. (2020). Display of native antigen on CDC1 that have spatial access to both $T$ and $B$ cells underlies efficient humoral vaccination. J. Immunol. 205, 1842-1856.

Khayat-Khoei, M., Bhattacharyya, S., Katz, J., Harrison, D., Tauhid, S., Bruso, P., Houtchens, M.K., Edwards, K.R., and Bakshi, R. (2021). COVID-19 mRNA vaccination leading to CNS inflammation: a case series. J. Neurol. https://doi. org/10.1007/s00415-021-10780-7.

Kozma, G.T., Shimizu, T., Ishida, T., and Szebeni, J. (2020). Anti-PEG antibodies: properties, formation, testing and role in adverse immune reactions to PEGylated nano-

biopharmaceuticals. Adv. Drug Deliv. Rev. 154 155, 163-175

Kulkarni, J.A. Cullis, P.R., and Van Der Meel, R. (2018). Lipid nanoparticles enabling gene therapies: from concepts to clinical utility. Nucleic Acid Ther. 28, 146-157.

Laczkó, D., Hogan, M.J., Toulmin, S.A., Hicks, P. Lederer, K., Gaudette, B.T., Castaño, D., Amanat, F., Muramatsu, H., Oguin, T.H., et al. (2020). A single immunization with nucleoside-modified mRNA vaccines elicits strong cellular and humoral immune responses against SARS-CoV-2 in mice. Immunity 53, 724-732.e7.

Lederer, K., Castaño, D., Gómez Atria, D., Oguin T.H., Wang, S., Manzoni, T.B., Muramatsu, H. Hogan, M.J., Amanat, F., Cherubin, P., et al. (2020). SARS-CoV-2 mRNA vaccines foster potent antigen-specific germinal center responses associated with neutralizing antibody generation. Immunity 53, 1281-1295.e5.

Li, J., Ahmet, F., Sullivan, L.C., Brooks, A.G., Kent, S.J., De Rose, R., Salazar, A.M., Reis e Sousa, C. Shortman, K. Lahoud, M.H. et al. (2015). Antibodies targeting Clec9A promote strong humoral immunity without adjuvant in mice and non-human primates. Eur. J. Immunol. 45, 854-864.

Liberzon, A., Subramanian, A., Pinchback, R. Thorvaldsdottir, H., Tamayo, P., and Mesirov, J.P. (2011). Molecular signatures database (MSigDB) 3.0. Bioinformatics 27, 1739-1740.

Lockman, P.R., Koziara, J.M., Mumper, R.J., and Allen, D.D. (2004). Nanoparticle surface charges alter blood-brain barrier integrity and permeability. J. Drug Target. 12, 635-641.

Lonez, C., Vandenbranden, M., and Ruysschaert, J.-M. (2012). Cationic lipids activate intracellular signaling pathways. Adv. Drug Deliv. Rev. 64, 1749-1758.

Lonez, C., Bessodes, M. Scherman, D. Vandenbranden, M., Escriou, V., and Ruysschaert J.-M. (2014). Cationic lipid nanocarriers activate Toll-like receptor 2 and NLRP3 inflammasome pathways. Nanomed. Nanotechnol. Biol. Med. 10, 775-782

Love, M.I., Huber, W., and Anders, S. (2014). Moderated estimation of fold change and dispersion for RNA-seq data with DESeq2 Genome Biol. 15, 550.

Lund, F.E., and Randall, T.D. (2021). Scent of a vaccine. Science 373, 397-399.
Lv, H., Zhang, S., Wang, B., Cui, S., and Yan, J. (2006). Toxicity of cationic lipids and cationic polymers in gene delivery. J. Control Release 114, 100-109

Marshall, M., Ferguson, I.D., Lewis, P., Jaggi, P. Gagliardo, C., Collins, J.S., Shaughnessya, R., Carona, R., Fuss, C., Corbin, K.J.E., et al. (2021). Symptomatic acute myocarditis in seven adolescents following pfizer-BioNTech COVID19 vaccination. Pediatrics 148, e2021052478.

Martins, S., Sarmento, B., Ferreira, D.C., and Souto, E.B. (2007). Lipid-based colloidal carriers for peptide and protein delivery-liposomes versus lipid nanoparticles. Int. J. Nanomed. 2, 595-607

Maugeri, M. Nawaz, M., Papadimitriou, A. Angerfors, A., Camponeschi, A., Na, M., Hölttä, M., Skantze, P., Johansson, S., Sundqvist, M., et al. (2019). Linkage between endosomal escape of LNP-mRNA and loading into EVs for transport to other cells. Nat. Commun. 10, 4333

Moderna. (2021). Assessment Report COVID-19 Vaccine Moderna Common. EMA/15689/2021 Corr.1*1 31, pp. 1-169. https://www.ema.europa. eu/en/documents/assessment-report/spikevaxpreviously-covid-19-vaccine-moderna-eparpublic-assessment-report_en.pdf.

Montgomery, J., Ryan, M., Engler, R., Hoffman, D., McClenathan, B., Collins, L., Loran, D., Hrncir, D. Herring, K., Platzer, M., et al. (2021). Myocarditis following immunization with mRNA COVID-19 vaccines in members of the US military. JAMA Cardiol. 6, 1202-1206.

Nair, A., and Jacob, S. (2016). A simple practice guide for dose conversion between animals and human. J. Basic Clin. Pharm. 7, 27

Ndeupen, S., Bouteau, A., Herbst, C., Qin, Z., Hutchins, Z., Kurup, D., Diba, L.Z., and Igyártó, B.Z. (2021). Langerhans cells and CDC1s play redundant roles in mRNA-LNP induced protective anti-influenza and anti-SARS-CoV-2 responses. BioRxiv Prepr. Serv. Biol. https://doi. org/10.1101/2021.08.01.454662.

Netea, M.G., Quintin, J., and van der Meer, J.W.M. (2011). Trained immunity: a memory for innate host defense. Cell Host Microbe. 9, 355-361.

Ols, S., Yang, L., Thompson, E.A., Pushparaj, P. Tran, K., Liang, F., Lin, A., Eriksson, B., Karlsson Hedestam, G.B. Wyatt, R.T. et al. (2020). Route of vaccine administration alters antigen trafficking but not innate or adaptive immunity. Cell Rep. 30, 3964-3971.e7.

Pardi, N., Tuyishime, S., Muramatsu, H., Karikó, K. Mui, B.L. Tam, Y.K. Madden, T.D. Hope, M.J., and Weissman, D. (2015). Expression kinetics of nucleoside-modified mRNA delivered in lipid nanoparticles to mice by various routes. J. Control Release 217, 345-351.

Pardi, N., Hogan, M.J., Pelc, R.S., Muramatsu, H., Andersen, $H$. DeMaso, C.R. Dowd, K.A. Sutherland, L.L., Scearce, R.M., Parks, R., et al. (2017). Zika virus protection by a single low-dose nucleoside-modified mRNA vaccination. Nature $543,248-251$

Pardi, N., Hogan, M.J., Naradikian, M.S., Parkhouse, K., Cain, D.W., Jones, L., Moody, 
M.A., Verkerke, H.P., Myles, A., Willis, E., et al. (2018a). Nucleoside-modified mRNA vaccines induce potent $T$ follicular helper and germinal center B cell responses. J. Exp. Med. 215, 15711588.

Pardi, N., Parkhouse, K., Kirkpatrick, E. McMahon, M., Zost, S.J., Mui, B.L., Tam, Y.K. Karikó, K., Barbosa, C.J., Madden, T.D., et al. (2018b). Nucleoside-modified mRNA immunization elicits influenza virus hemagglutinin stalk-specific antibodies. Nat. Commun. 9, 3361.

Patone, M., Handunnetthi, L., Saatci, D., Pan, J. Katikireddi, S.V., Razvi, S., Hunt, D., Mei, X.W., Dixon, S., Zaccardi, F., et al. (2021). Neurological complications after first dose of COVID-19 vaccines and SARS-CoV-2 infection. Nat. Med. https://doi.org/10.1038/s41591-021-01556-7.

Russell, M.W., Moldoveanu, Z., Ogra, P.L., and Mestecky, J. (2020). Mucosal immunity in COVID19: a neglected but critical aspect of SARS-CoV-2 infection. Front. Immunol. 11, 611337

Sahin, U., Muik, A., Derhovanessian, E., Vogler, I., Kranz, L.M., Vormehr, M., Baum, A., Pascal, K., Quandt, J., Maurus, D., et al. (2020). COVID-19 vaccine BNT162b1 elicits human antibody and TH1 T cell responses. Nature 586, 594-599.

Samaridou, E., Heyes, J., and Lutwyche, P. (2020). Lipid nanoparticles for nucleic acid delivery: current perspectives. Adv. Drug Deliv. Rev. 154 $155,37-63$.

Sedic, M., Senn, J.J., Lynn, A., Laska, M., Smith M., Platz, S.J., Bolen, J., Hoge, S., Bulychev, A. Jacquinet, E., et al. (2018). Safety evaluation of lipid nanoparticle-formulated modified mRNA in the sprague-dawley rat and cynomolgus monkey. Vet. Pathol. 55, 341-354.

Shay, D.K., Shimabukuro, T.T., and DeStefano, F. (2021). Myocarditis occurring after immunization with mRNA-based COVID-19 vaccines. JAMA Cardiol. 6, 1115-1117

Shirai, S., Shibuya, M., Kawai, A., Tamiya, S. Munakata, L., Omata, D., Suzuki, R., Aoshi, T., and
Yoshioka, Y. (2020). Lipid nanoparticles potentiate CpG-oligodeoxynucleotide-based vaccine for influenza virus. Front. Immunol. 10, 3018

Shrum, B., Anantha, R.V., Xu, S.X., Donnelly, M., Haeryfar, S., McCormick, J.K., and Mele, T. (2014). A robust scoring system to evaluate sepsis severity in an animal model. BMC Res. Notes 7. 233.

Sterlin, D. Mathian, A. Miyara, M., Mohr, A Anna, F., Claër, L., Quentric, P., Fadlallah, J., Devilliers, H., Ghillani, P., et al. (2021). IgA dominates the early neutralizing antibody response to SARS-CoV-2. Sci. Transl. Med. 13, 2223

Su, Q. Bouteau, A., Cardenas, J., Uthra, B. Wang, Y., Smitherman, C., Gu, J., and Igyártó, B.Z. (2020). Brief communication: long-term absence of Langerhans cells alters the gene expression profile of keratinocytes and dendritic epidermal T cells. PLoS One 15, e0223397.

Subramanian, A., Tamayo, P., Mootha, V.K., Mukherjee, S., Ebert, B.L., Gillette, M.A. Paulovich, A., Pomeroy, S.L., Golub, T.R. Lander E.S., et al. (2005). Gene set enrichment analysis: knowledge-based approach for interpreting genome-wide expression profiles. Proc. Natl. Acad. Sci. U S A 102, 15545-15550.

Swaminathan, G., Thoryk, E.A., Cox, K.S., Smith, J.S. Wolf, J.J. Gindy, M.E. Casimiro, D.R and Bett, A.J. (2016). A tetravalent sub-unit dengue vaccine formulated with ionizable cationic lipid nanoparticle induces significant immune responses in rodents and non-human primates. Sci. Rep. 6, 34215.

Szebeni, J. (2005). Complement activationrelated pseudoallergy: a new class of druginduced acute immune toxicity. Toxicology 216, 106-121.

Szebeni, J. (2014). Complement activationrelated pseudoallergy: a stress reaction in blood triggered by nanomedicines and biologicals. Mol. Immunol. 61, 163-173.
Tanaka, T., Legat, A., Adam, E., Steuve, J., Gatot, J.S. Vandenbranden, M. Ulianov, L., Lonez, C. Ruysschaert, J.-M., Muraille, E., et al. (2008). DiC14-amidine cationic liposomes stimulate myeloid dendritic cells through Toll-like receptor 4. Eur. J. Immunol. 38, 1351-1357.

Tanaka, T., Narazaki, M., and Kishimoto, T. (2014). IL-6 in inflammation, immunity, and disease. Cold Spring Harb. Perspect. Biol. 6, a016295.

Tao, W., Mao, X., Davide, J.P., Ng, B., Cai, M. Burke, P.A., Sachs, A.B., and Sepp-Lorenzino, L. (2011). Mechanistically probing lipid-sirna nanoparticle-associated toxicities identifies jak inhibitors effective in mitigating multifaceted toxic responses. Mol. Ther. 19, 567-575

Walsh, E.E., Frenck, R.W., Falsey, A.R., Kitchin, N. Absalon, J., Gurtman, A., Lockhart, S., Neuzil, K., Mulligan, M.J., Bailey, R., et al. (2020). Safety and immunogenicity of two RNA-based covid-19 vaccine candidates. N. Engl. J. Med. 383, 24392450.

Wherry, E.J., and Kurachi, M. (2015). Molecular and cellular insights into $\mathrm{T}$ cell exhaustion. Nat. Rev. Immunol. 15, 486-499.

Yao, C., Zurawski, S.M., Jarrett, E.S., Chicoine, B., Crabtree, J., Peterson, E.J., Zurawski, G., Kaplan, D.H., and Igyártó, B.Z. (2015). Skin dendritic cells induce follicular helper $\mathrm{T}$ cells and protective humoral immune responses. J. Allergy Clin. mmunol. 136, 1387-1397.e7.

Yu, Y.-R.A., O'Koren, E.G., Hotten, D.F., Kan, M.J., Kopin, D., Nelson, E.R., Que, L., and Gunn, M.D. (2016). A protocol for the comprehensive flow cytometric analysis of immune cells in normal and inflamed murine non-lymphoid tissues. PLoS One 11, e0150606.

Zens, K.D., Chen, J.K., and Farber, D.L. (2019) Vaccine-generated lung tissue-resident memory $\mathrm{T}$ cells provide heterosubtypic protection to influenza infection. JCl Insight 1, e85832. 


\section{STAR $\star$ METHODS}

\section{KEY RESOURCES TABLE}

\begin{tabular}{|c|c|c|}
\hline REAGENT or RESOURCE & SOURCE & IDENTIFIER \\
\hline \multicolumn{3}{|l|}{ Antibodies } \\
\hline CD11b - BV711 & BioLegend & BioLegend Cat\# 101242; RRID:AB_2563310 \\
\hline CD11c - PeCy7 & BioLegend & BioLegend Cat\# 117318; RRID:AB_493568 \\
\hline CD24 - PE-Cy5 & BioLegend & BioLegend Cat\# 101811; RRID:AB_439713 \\
\hline CD45 - BUV395 & BD Biosciences & $\begin{array}{l}\text { BD Biosciences Cat\# 564279; } \\
\text { RRID:AB_2651134 }\end{array}$ \\
\hline CD64 - BV605 & BioLegend & BioLegend Cat\# 139323; RRID:AB_2629778 \\
\hline MHCII - AF700 & BioLegend & BioLegend Cat\# 107622; RRID:AB_493727 \\
\hline Ly6C - FITC & BioLegend & BioLegend Cat\# 128006; RRID:AB_1186135 \\
\hline Ly-6G - BV510 & BioLegend & BioLegend Cat\# 127633; RRID:AB_2562937 \\
\hline $\mathrm{F} 4 / 80-\mathrm{PB}$ & BioLegend & BioLegend Cat\# 123124; RRID:AB_893475 \\
\hline eF780-live/dead & Fisher Scientific & Fisher Scientific Cat\# BDB564279; NA \\
\hline Fc-block & BioLegend & BioLegend Cat\# 422302; RRID:AB_2818986 \\
\hline \multicolumn{3}{|l|}{ Biological samples } \\
\hline Mouse tissues and organs & Mice & N/A \\
\hline \multicolumn{3}{|l|}{ Critical commercial assays } \\
\hline RNeasy Mini Kit & Qiagen & Cat\# 74104 \\
\hline RNA 6000 Pico Kit & Agilent & Cat\# 5067-1513 \\
\hline $\begin{array}{l}\text { Bio-Plex Pro }{ }^{T M} \text { Mouse Chemokine Panel 33- } \\
\text { Plex }\end{array}$ & Bio-Rad & Cat\# 12002231 \\
\hline \multicolumn{3}{|l|}{ Deposited data } \\
\hline RNA-seq data & This paper & GSE167521 \\
\hline \multicolumn{3}{|l|}{ Experimental models: Organisms/strains } \\
\hline Mouse C57BL/6J & The Jackson Laboratory & Stock No: 000664 \\
\hline \multicolumn{3}{|l|}{ Software and algorithms } \\
\hline FlowJo ${ }^{T M}$ v10.8 & BD Biosciences & https://www.flowjo.com/ \\
\hline GraphPad Prism 9 & GraphPad & https://www.graphpad.com/ \\
\hline \multicolumn{3}{|l|}{ Other } \\
\hline Different lipid nanoparticle formulations & Dr. Norbert Pardi/Acuitas & N/A \\
\hline
\end{tabular}

\section{RESOURCE AVAILABILITY}

\section{Lead contact}

Further information and requests should be directed to the lead contact, Botond Z. Igyártó (botond.

igyarto@jefferson.edu).

\section{Materials availability}

This study did not generate new unique reagents.

Data and code availability

- The RNA-seq data can be found at the following GEO accession number: GSE167521

- This paper does not report original code.

- Any additional information required to reanalyze the data reported in this paper is available from the lead contact upon request. 


\section{EXPERIMENTAL MODEL AND SUBJECT DETAILS}

\section{Mice}

WT C57BL/6J mice of different ages and gender were purchased from Jax® or bred in house. All experiments were performed with 6-12 weeks old male and female mice. Mice were housed in microisolator cages and fed autoclaved food. Institutional Care and Use Committee approved all mouse protocols.

\section{METHOD DETAILS \\ Reagents}

For our studies, we used an LNP formulation proprietary to Acuitas Therapeutics described in US patent US10,221,127. These LNPs were previously carefully characterized and widely tested in preclinical vaccine studies in combination with nucleoside-modified mRNAs (Laczkó et al., 2020; Lederer et al., 2020; Pardi et al., 2017, 2018a, 2018b). The following LNP formulations were used: empty LNPs with or without proprietary ionizable lipid, Dil-labeled LNPs, and LNPs complexed with non-coding poly-cytosine mRNA. The mRNA:lipid mass ratio was 1:20.

\section{Intradermal inoculation and flow cytometry analyses}

The day before injections, the hair from the back skin of adult WT B6 mice was removed using an electric clipper, and then the site of injections wet-shaved using Personna razor blades. The next day the mice were injected intradermally with $2.5 \mu \mathrm{g} / \mathrm{spot}$ LNPs in PBS (4 spots, $10 \mu \mathrm{g}$ total) or PBS. At different time points post-injection, the mice were sacrificed and $\sim 1 \mathrm{~cm}^{2}$ skin around the injection site harvested. The skin samples were then chopped into small pieces using a curved scissor and exposed to collagenase/hyaluronidase digestion (Kashem and Kaplan, 2018). Single-cell suspensions were stained for the following markers: fixable viability dye (Thermo Fisher), MHC-II, CD11b, CD11c, CD45, CD64, F4/80, and Ly6G (All from BioLegend, except CD45 was from BD). The stained samples were run on LSRFortessa ${ }^{\text {TM }}$ (BD Biosciences) and the resulting data analyzed with FlowJo 10.

\section{Intramuscular inoculation and flow cytometry analyses}

Cohorts of WT mice were injected with $10 \mu \mathrm{g}$ of LNPs in $30 \mu \mathrm{l}$ of PBS or PBS alone in the quadriceps of the right posterior limb. The muscle samples were harvested 24 hours later, chopped into small pieces using a curved scissor and exposed to collagenase/hyaluronidase digestion as described for the skin samples. Single-cell suspensions were stained for the following markers: fixable viability dye (Thermo Fisher), CD45, and Ly6G (All from BioLegend).

\section{Luminex ${ }^{\circledR}$}

The day before injections, the hair from the back skin of adult WT B6 mice was removed using an electric clipper, and then the site of injections wet-shaved using Personna razor blades. The next day the mice were injected intradermally with $2.5 \mu \mathrm{g}$ /spot LNPs complexed with non-coding poly-cytosine mRNA or PBS (Figure 2A). Twenty-four hours later, the skin samples were collected and processed for Luminex $\AA$ and RNAseq. The samples for Luminex were weighed and homogenized using a Dounce tissue grinder in $1.5 \mathrm{ml}$ of $10 \mathrm{mM}$ Tris $\mathrm{pH} 7.4,150 \mathrm{mM} \mathrm{NaCl}, 1 \%$ Triton-X-100 per gram of tissue in the presence of Roche protease inhibitor cocktail. After incubation on ice for 30 minutes, the samples were spun at 10K RPM for 10 minutes at $4^{\circ} \mathrm{C}$. The supernatants were harvested and filtered with a $0.22 \mu \mathrm{m}$ Eppendorf tube filter (MilliporeSigma). The supernatants were aliquoted and kept at $-80^{\circ} \mathrm{C}$ until further use. The samples were tested using the Bio-Plex Pro ${ }^{\mathrm{TM}}$ Mouse Chemokine Panel 33-Plex as per manufacturer's instruction.

\section{RNA preparation, sequencing, data analyses and visualization}

Total RNA was isolated from tissue lysates using the RNeasy Mini Kit (Qiagen), including on-column DNase digestion. Total RNA was analyzed for quantity and quality using the RNA 6000 Pico Kit (Agilent). Sequencing, data analyses and visualization were performed as we and others previously described in details (Kanehisa, 2000; Liberzon et al., 2011; Love et al., 2014; Su et al., 2020; Subramanian et al., 2005).

\section{Intranasal inoculation and flow cytometry analyses}

Mice were anesthetized by intraperitoneal injection with a mixture of Xylazine/Ketamine. The LNPs were given intranasally at the doses of $2.5,5$ and $10 \mu \mathrm{g}$ in $30 \mu \mathrm{L}$ sterile PBS by placing droplets gently on the left nostril and allowed the mice to inhale. The clinical performances of the mice were scored daily for 


\section{iScience}

8 days as described previously (Shrum et al., 2014). Besides, the body weight was also measured daily. Some of the mice from the $10 \mu \mathrm{g}$ LNP dose and corresponding PBS controls were sacrificed at indicated time points post-inoculation, and lung samples were harvested for histology and flow cytometry. For histology, the samples were fixed in 4\% PFA overnight and then embedded in OCT. Eight micrometer thick sections were prepared using a cryostat and counterstained with DAPI. Stitched confocal pictures were taken using a Nikon A1 microscope. The lung samples for flow cytometry were digested using the collagenase/hyaluronidase technique also used for the skin samples (Kashem and Kaplan, 2018). The resulting single-cell suspensions were stained with the following markers: fixable viability dye (Thermo Fisher), MHC-II, CD11b, CD11c, CD24, CD45, CD64, Ly6G and Ly6C (All from BioLegend, except CD45 was from BD) (Yu et al., 2016).

\section{QUANTIFICATION AND STATISTICAL ANALYSIS}

All data were analyzed with GraphPad Prism version 9.0.0. Statistical methods used to determine significance are listed under each figure. 